\title{
Investigations on reactivity of sera in endemic syphilis from Bosnia 20 years after treatment
}

\author{
MIRA NADAŽDIN AND KSENIJA KARLOVAC \\ From the Institute of Dermato-Venerology, Yugoslavia
}

SUMMARY Sera from 225 patients who 20 years earlier had been infected with endemic syphilis and adequately treated with penicillin (PAM 4.8-6 megaunits) at various stages of the disease, were investigated for serological reactivity by the fluorescent treponemal antibody absorption (FTA-ABS), treponemal haemagglutination, and Venereal Diseases Research Laboratory tests. Specific antibodies were found in a large percentage of cases and their presence may be assumed to depend on persisting specific antigen which stimulates their synthesis.

\section{Introduction}

Endemic syphilis is found in rural populations with a low standard of education and primitive sanitary and housing conditions. It has a non-venereal mode of transmission indirectly by use of common utensils and directly by daily contact in places where infection is encouraged by poor hygienic conditions. Endemic syphilis, therefore, has the characteristics of a family disease.

Endemic syphilis was introduced into Bosnia and Herzegovina in the eighteenth century. It was more common in the north-western, central, and eastern parts of Bosnia than in Herzegovina. There is no information about the extent of the disease when the region was under Turkish domination, but during the Austro-Hungarian occupation of Bosnia and Herzegovina at the end of the nineteenth century endemic syphilis was widespread.

After the collapse of the Austro-Hungarian Empire the situation was improved by the syphilis control programmes of 1926-33, carried out by the Yugoslavian public health administration. However during the second world war the situation deteriorated with the migration of refugees, a lower standard of living, and poor hygiene, which gave rise to new endemic foci in the rural areas.

After the war the problem of endemic syphilis became one of the priorities of the public health administration in the new Yugoslavia. With technical assistance from WHO and UNICEF a well organised

Address for reprints: N. Nadaždin, Institute of Dermato-Venerology, Sarajevo, PO Box 137, Yugoslavia

Received for publication 6 January 1977 field eradication campaign was conducted from 1948 to 1953 by the health administration of the Republic of Bosnia and Herzegovina (Grin, 1953).

In this mass treatment campaign penicillin was used if there were clinical, serological, or epidemiological indications. The campaign ended successfully and endemic syphilis in Bosnia and Herzegovina became merely of historical interest (Grin and Guthe, 1973).

We are interested to determine the present prevalence of serological activity in those patients who were infected with endemic syphilis and given adequate treatment (4.8-6 megaunits of PAM) 20 years ago.

\section{Materials and methods}

The investigation comprised 225 sera from patients infected with endemic syphilis and treated with penicillin at various stages of the infection 20 years ago, and who now have no clinical manifestations of the disease.

The sera were collected from various parts of Bosnia where endemic syphilis was prevalent. In the field survey, the household cards which were completed during the village census were used. Special cards were used to record information on individuals on whom personal, clinical, and serological data were available in the central registry from the previous mass campaign. The field procedures comprised history taking, clinical examination, and venepuncture.

Since our earlier investigations showed that age might have a considerable effect on serological reactivity (Grin and Nadaždin, 1968), the people were divided into age groups $(20-29,30-44,45-59$, 
Table 1 Results of FTA-ABS, TPHA, and VDRL tests in endemic syphilis according to age

\begin{tabular}{|c|c|c|c|c|c|c|c|}
\hline \multirow{2}{*}{$\begin{array}{l}\text { Age group } \\
\text { (years) }\end{array}$} & \multirow[t]{2}{*}{ No. tested } & \multicolumn{2}{|c|}{$F T A-A B S$ reactive } & \multicolumn{2}{|c|}{ TPHA reactive } & \multicolumn{2}{|c|}{$V D R L$ reactive } \\
\hline & & No. & $\%$ & No. & $\%$ & No. & $\%$ \\
\hline $20-29$ & 7 & 3 & $42 \cdot 8$ & 4 & $57 \cdot 1$ & 4 & $57 \cdot 1$ \\
\hline $30-44$ & 69 & 52 & $75 \cdot 4$ & 62 & 89.8 & 31 & 44.9 \\
\hline $45-59$ & 91 & 71 & 78.0 & 77 & $84 \cdot 6$ & 44 & $48 \cdot 3$ \\
\hline $60+$ & 58 & 44 & 75.9 & 52 & $89 \cdot 7$ & 25 & $43 \cdot 1$ \\
\hline Total & 225 & 177 & $75 \cdot 5$ & 195 & 86.7 & 104 & $46 \cdot 2$ \\
\hline
\end{tabular}

Table 2 Results of FTA-ABS, TPHA, and VDRL tests in endemic syphilis treated 20 years ago

\begin{tabular}{|c|c|c|c|c|c|c|c|}
\hline \multirow{2}{*}{$\begin{array}{l}\text { Stage of disease } \\
\text { at treatment }\end{array}$} & \multirow[t]{2}{*}{ No. tested } & \multicolumn{2}{|c|}{$F T A$ reactive } & \multicolumn{2}{|c|}{ TPHA reactive } & \multicolumn{2}{|c|}{$V D R L$ reactive } \\
\hline & & No. & $\because$ & No. & $\%$ & No. & $\%$ \\
\hline \multicolumn{8}{|l|}{ Syphilis } \\
\hline early & 60 & 44 & $73 \cdot 3$ & 58 & $96 \cdot 7$ & 29 & $48 \cdot 4$ \\
\hline latent & 160 & 124 & $77 \cdot 5$ & 133 & $83 \cdot 1$ & 71 & $44 \cdot 4$ \\
\hline late & 5 & 5 & $100 \cdot 0$ & 4 & 80.0 & 4 & 80.0 \\
\hline Total & 225 & 173 & $76 \cdot 9$ & 195 & $86 \cdot 7$ & 104 & $46 \cdot 2$ \\
\hline
\end{tabular}

$60+$ years). The sera were placed in three groups according to the stage of disease at which the patients had been treated.

The sera were examined by the treponemal haemagglutination (TPHA) test (Tomizawa, 1966), fluorescent treponemal antibody-absorption (FTAABS) test using the standard sorbent prepared in our laboratory by the method of Stout et al. (1967), and the Venereal Diseases Research Laboratory (VDRL) test.

\section{Results and discussion}

The results related to the present age of the patients are presented in Table 1 . With the possible exception of the small number of patients in the youngest age group (20-29 years) there were no marked differences in serological reactivity.

The results presented in Table 2 show that the sera from those first treated in the early stage of infection were reactive in the FTA-ABS test in $73.3 \%$. In those who had been in the latent stage, the immunoglobulins reactive in the FTA-ABS test were present to a slightly larger extent $(77.5 \%)$. These differences in reactivity, according to the stage of the infection at which treatment was started, are trivial particularly if it is taken into account that treatment was carried out 20 years ago.

The FTA-ABS test gave positive results in all five patients who had had gummatous manifestations before treatment.

Antibodies detected by the TPHA test persisted in a large percentage of treated patients; sera from $96.7 \%$ of patients who had been in the early stage of infection before treatment were still reactive, and among those in the latent stage $83.1 \%$ were found reactive.
Comparing the results of the TPHA test with the results of the FTA-ABS method it can be seen that in general the TPHA test was positive in a larger percentage.

There were also a surprisingly large number of sera with VDRL reactivity. Of those who had been in the early stage of syphilis before treatment the sera in $48.4 \%$ were reactive, and $44.4 \%$ in the latent stage were still reactive.

The serological reactivity as assessed by the FTA-ABS, TPHA, and VDRL tests persisting for 20 years after penicillin treatment suggests that the behaviour of endemic syphilis differs from venereal syphilis. Although serological reactivity persisted for many years, clinical cure was achieved.

We have to assume that the presence of specific antibodies in adequately treated patients depends on persisting treponemal antigens; it is not clear if these are live treponemes maintained in a quiescent phase by immunological balance, or residual treponemal material which has not been entirely metabolised.

\section{References}

Grin, E. I. (1953) Epidemiology and Control of Endemic Syphilis. Monograph Series No. 11. WHO: Geneva.

Grin, E. I., and Guthe, T. (1973). Evaluation of a previous mass campaign against endemic syphilis in Bosnia and Herzegovina. British Journal of Venereal Diseases, 49, 1-19.

Grin, E. I., and Nadaždin, M. (1968). Non-specific reactions to the quantitative fluorescent antibody test (FTA) in the elderly. British Journal of Venereal Diseases, 43, 216-217.

Stout, G. W., Kellogg, D. S. Jr, Falcone, V. H., McGrew, B. E., and Lewis, J. S. (1967). Preparation and standardization of the sorbent used in the fluorescent treponemal antibody-absorption (FTAABS) test. Health Laboratory Science, 4, 5-8.

Tomizawa, T. (1966). Hemagglutination tests for diagnosis of syphilis. A preliminary report. Japanese Journal of Medical Science and Biology, 19, 305-308. 